Review Article

\title{
Game Playing and Problem-Solving Self-Efficacy
}

\author{
Shwu-Huey Wang * \\ Department of Innovative Design and Entrepreneurship Management, Far East University, Taiwan
}

\section{*Corresponding Author}

Shwu-Huey Wang

\section{Article History}

Received: 30.09 .2020

Accepted: 22.10 .2020

Published: 30.10 .2020

\begin{abstract}
Modern advanced computer technology has been greatly applied to areas of our daily lives, especially how to enhance problem-solving ability. As the modern young generation grew up in a digital world and game-playing seemed to have become a ubiquitous pastime in their usual lives. In order to understand if game is effective in improving students' problem-solving ability, this study employs game to facilitate students' problem-solving ability. The related literature was reviewed and the researcher proposed several propositions based on the reviewed literature. It is anticipated that game playing will be applied to education in the future more and more from different areas of profession and hopefully students' learning performance would be improved more easily.
\end{abstract}

Keywords: Information innovative application, game, problem-solving.

\section{INTRODUCTION}

When computer technology has been more and more utilized in our daily lives, educators started to consider how to improve students' learning through the help of information technology. On the other side, students have to practically face different cases or problems after they go to work, in other words, the challenging practice are testing or examining their problem-solving ability. However, the traditional instruction still lives a gap between class learning and practice application [1]. Moreover, both Oblinger [2] and Foreman [3] argued that the conventional way, for example : lecture-based format, may not be so advantageous to keep student' learning interest, this leaves students to have much space to be learned in problem solving.

Today's young people grew up in a digital world and one of their biggest pastimes is playing games, this makes the idea of game-based learning greatly attract people's attention in the recent years. The different instruction has not only enabled learning to be more interesting but also driven educators to ponder over the efficiency of game-based pedagogy in facilitating students' learning. In addition, computer games have also been regarded as powerful learning tools with great motivational appeals and multiple representations of learning materials $[4,5]$. Therefore, it is important to provide different ways that they could relate to and learn from.

Although it is generally accepted that computer games are an extremely motivating and engaging medium, within the field of hospitality management, there is still a dearth of empirical evidence to support this approach. Therefore, the aim of this study is to understand if epistemic games could facilitate hospitality students' learning outcomes in solving problems?

\section{THEORETICAL FoundaTion}

\section{Information innovation application and education}

Information innovation application has been greatly applied to education in the recent decade. For example: educators have been using a number of commercial off-the-shelf games as one effective method for teaching social studies. For example, Squire [6] employed Civilization III to improve students historical concepts in school classes, the results indicated that the game was quite helpful in enhancing students' ability to propose alternative approaches, which thereby highly lifted students learning performance. Later, Egenfeldt-Nielsen [7] utilized Europa Universalis II in a high

Copyright $(\mathbf{2} 2020$ The Author(s): This is an open-access article distributed under the terms of the Creative Commons Attribution 4.0 International License (CC BY-NC 4.0) which permits unrestricted use, distribution, and reproduction in any medium for noncommercial use provided the original author and source are credited. 
school with an attempt to improve the young students' learning in history class. The results showed that the game was very beneficial in increasing students' class understanding for most of the participants. Adams [8] used SimCity 2000, a commercial off-the-shelf game, in an undergraduate introductory urban geography class to have students challenge various aspects of complex problems in terms of urban planning. The contents presents in the form of different scenarios. Consequently, the participants greatly appreciated the achievements learned from the game-playing. They even presented that the game had became their favorite.

Based on the above cases, it is evident that, game, the most representative modern information innovation technology would be an influential and effective way to improve students' problem-solving ability.

\section{Game playing and problem-solving self-efficacy}

In the past years, self-efficacy has attached more and more attention on evaluating academic achievements. Prior research $[9,10]$ reported that self-efficacy is the most powerful factor in forecasting students' academic performance than any other internal motivation component. As noted, students with high self-efficacy will tend to engage more energy in a complicated case and hold on straight with it when they run into difficulties or obstacles. In other words, students' beliefs in efficacy can powerfully influence and regulate their learning, control their academic activities, guide their level of motivation and promote their academic accomplishments [11].

Accordingly, the features of game-playing rightly abbreviated the gaps between student's self-efficacy and problem-solving ability. It becomes easy for educators to facilitate students' problem-solving ability through their increased self-efficacy, which resulted from the game-playing. Evidently, information innovation application such as game would be an effective way to facilitate novice people's problem solving. The study is therefore propose the propositions as the following:

\section{Propositions}

Based on the literature reviewed above, the study is therefore proposing the related propositions as the following:

Proposition 1: Epistemic game-playing is effective in enhancing students' problem-solving ability.

Proposition 2: Epistemic game-playing is beneficial in increasing students' problem-solving self-efficacy.

Proposition 3: Epistemic game-playing is helpful in improving students' higher level thinking ability.

\section{CONCLUSION}

This study applied modern information innovation, epistemic game, to facilitate students' problem solving ability, the most important contribution of this study is that in the hospitality education area. The applicability of this study is worthy to be encouraged. Moreover, it is quite notable that we can understand that young students hold quite favorable comments about the instruction. This enlights educators that some of the difficulties that happened in the class would be easily fixed by way of a different thinking. What we would like to emphasis is that learning is originally a "serious" event, but how to make learning be effective through the help of computer innovation application is the issue that we should deeply consider. On the other hand, "play is the nature of human beings", therefore, is it possible for us to link "play" and "learning" together and make learning be effective and different? The results have provided strong evidence that the way we employed is feasible.

Therefore, this study predicts that in our foreseeable future, the highly improved computer innovation application would be more and more popular not only in education but also in various areas of our daily lives.

\section{REFERENCES}

1. Cheng, Y., \& Wang, S. (2011). Applying a 3D virtual learning environment to facilitate student's application ability - The case of Marketing. Computers in Human Behavior, 27 (1), 576-584.

2. Oblinger, D. (2003). Boomers, Gen-Xers and Millennials: Understanding the new students. EDUCAUSE Review, $38(4), 36-45$.

3. Foreman, J. (2003). Next generation: Educational technology versus the lecture. EDUCAUSE Review, 38(4),12-22.

4. Betz, J. A. (1995). Computer games: Increases learning in an interactive multidisciplinary environment. Journal of Educational Technology Systems, 24, 195-205.

5. Moreno, R. (2002). Who learns best with multiple representations? Cognitive theory implications for individual differences in multimedia learning. Paper presented at World Conference on Educational Multimedia, Hypermedia, \& Telecommunications. Denver, CO.

6. Squire, K. D. (2004) Replaying history: Learning world history through playing Civilization III. Unpublished doctoral dissertation, Indiana University, Bloomington, IN. Retrieved from http://website.education.wisc.edu/kdsquire/dissertation.html 
7. Egenfeldt-Nielsen, S. (2005). Beyond edutainment: Exploring the educational potential of computer games $\left(2^{\text {nd }}\right.$ ed.).

8. Adams, P. C. (1998). Teaching and learning with SimCity 2000. Journal of Geography, 97 (2), 47-55.

9. Lent, R. W., Brown, S. D., \& Larkin, K. C. (1987). Comparison of three theoretically derived variables in predicting career and academic behavior: Self-efficacy, interest congruence, and consequence thinking. Journal of Counseling Psychology, 34, 293-298.

10. Pintrich, P. R., \& De Groot, E. (1990). Motivational and self-regulated learning components of classroom academic performance. Journal of Educational Psychology, 82, 33-40.

11. Bandura, A. (1993). Perceived self-efficacy in cognitive development and functioning. Educational Psychologist, 28(2), 117-148. 